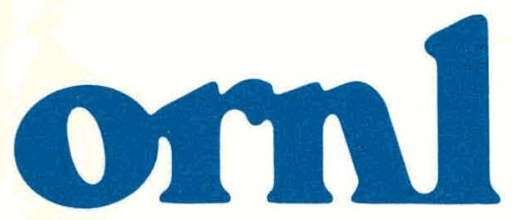

OAK RIDGE NATIONAL LABORATORY

UNION CARBIDE

\section{Dependence of Stability of Metastable Superconductors on Copper Fraction}

S. A. Elrod

J.W. Lue

J. R. Miller

L. Dresner
OPERATED BY

UNION CARBIDE CORPORATION FOR THE UNITED STATES DEPARTMENT OF ENERGY 


\section{DISCLAIMER}

This report was prepared as an account of work sponsored by an agency of the United States Government. Neither the United States Government nor any agency Thereof, nor any of their employees, makes any warranty, express or implied, or assumes any legal liability or responsibility for the accuracy, completeness, or usefulness of any information, apparatus, product, or process disclosed, or represents that its use would not infringe privately owned rights. Reference herein to any specific commercial product, process, or service by trade name, trademark, manufacturer, or otherwise does not necessarily constitute or imply its endorsement, recommendation, or favoring by the United States Government or any agency thereof. The views and opinions of authors expressed herein do not necessarily state or reflect those of the United States Government or any agency thereof. 


\section{DISCLAIMER}

Portions of this document may be illegible in electronic image products. Images are produced from the best available original document. 


\section{Printed in the United States of America. Available from National Technical Information Service \\ U.S. Department of Commerce 5285 Port Royal Road, Springfield, Virginia 22161 NTIS price codes-Printed Copy: A03 Microfiche A01}

This report was prepared as an account of work sponsored by an agency of the United States Government. Neither the United States Government nor any agency thereof, nor any of their employees, makes any warranty, express or implied, or assumes any legal liability or responsibility for the accuracy, completeness, or usefulness of any information, apparatus, product, or process disclosed, or represents that its use would not infringe privately owned rights. Reference herein to any specific commercial product, process, or service by trade name, trademark, manufacturer, or otherwise, does not necessarily constitute or imply its endorsement, recommendation, or favoring by the United States Government or any agency thereof. The views and opinions of authors expressed herein do not necessarily state or reflect those of the United States Government or any agency thereof. 
Contract No. W-7405-eng-26

\section{FUSION ENERGY DIVISION}

DEPENDENCE OF STABILITY OF METASTABLE SUPERCONDUCTORS ON COPPER FRACTION

S. A. Elrod, * J. W. Lue, J. R. Miller, and L. Dresner

NOTICE This document contains information of a preliminary nature. It is subject to revision or correction and therefore does not represent a final report.

Date Published - December 1980

* Oak Ridge Associated Universities Research Intern (March-August 1980)

Prepared by the OAK RIDGE NATIONAL LABORATORY

Oak Ridge, Tennessee 37830

operated by

UNION CARBIDE CORPORATION

for the

DEPARTMENT OF ENERGY 


\section{THIS PAGE}

\section{WAS INTENTIONALLY \\ LEFT BLANK}


CONTENTS

ABSTRACT $\ldots \ldots \ldots \ldots \ldots \ldots \ldots \ldots \ldots \ldots \ldots \ldots \ldots \ldots \ldots \ldots \ldots \ldots \ldots \ldots \ldots \ldots$

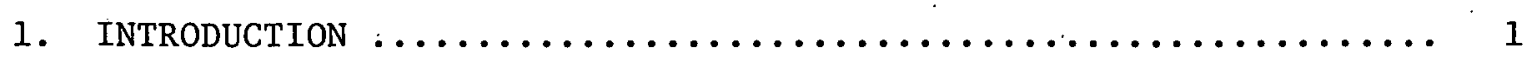

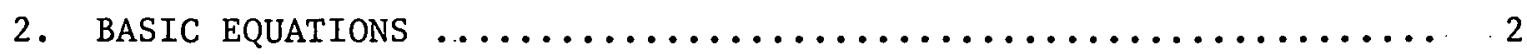

3. CONNECTION BETWEEN MPZ VOLTAGE AND ENERGY ................ 3

4. CALCULATION OF THE MPZ ..........................

5. USE OF THE $\varepsilon$ CONTOURS TO SELECT A Cu/SC RATIO .............. 10

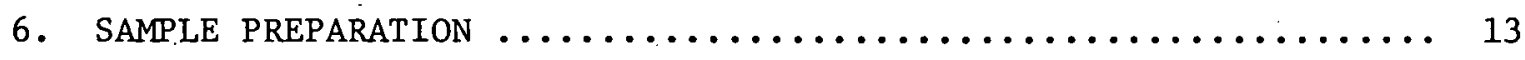

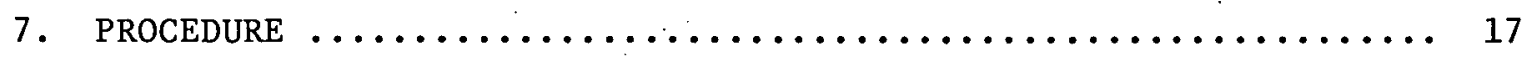

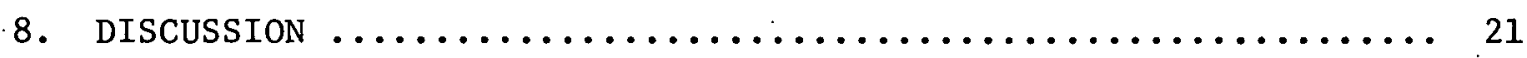

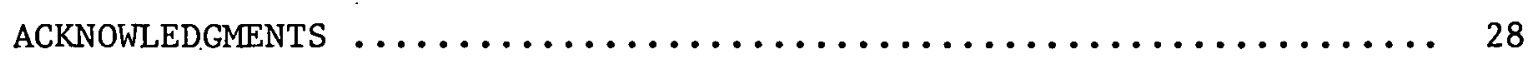

SYMBOLS .......................................... 29

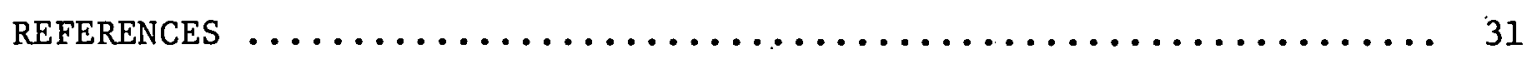




\section{THIS PAGE WAS INTENTIONALLY LEFT BLANK}


The stability of composite superconductors operating in the metastable regime depends upon such factors as matrix resistivity, cooled surface dimensions, fraction of critical current, and volume fraction of stabilizer. By assuming constant thermophysical properties, we developed analytic expressions for the energy and voltage of the minimum propagating zone (MPZ). With other factors held constant, these expressions have been used to predict composite superconductor stability as a function of copper fraction: lower copper fractions lead to higher MPZ energies. MPZ voltages have been measured for three $\mathrm{NbTi} / \mathrm{Cu}$ composites having different copper fractions and different critical current den- . sities for several magnetic fields and transport currents. Experimental MPZ voltages have been used to calculate an effective heat transfer coefficient, which is subsequently used to calculate the MPZ energy. The experimental MPZ energies support the theoretical expectation that lower copper fractions lead to higher stability in the metastable regime. 


\section{INTRODUCTION}

If subjected to a large enough perturbation, a metastable superconducting magnet will quench. As a result, the magnet designer of ten tries to choose the conductor that can sustain the largest perturbation without quenching. In Sect. 5 it is shown that for metastable conductors low copper fractions are to be preferred. To test this conclusion, we have studied the dependence of the minimum propagating zone (MPZ) energy (E) on copper-to-superconductor ratio for $\mathrm{NbTi} / \mathrm{Cu}$ superconductors having nearly identical geometries $\left(A=6.1 \times 10^{-6} \mathrm{~m}^{2}, \mathrm{P}=2.7 \times 10^{-3} \mathrm{~m}\right.$ ) but having copper fractions $(f)$ of $0.85,0.84$, and 0.79 and NbTi critical current densities $\left(\mathrm{J}_{\mathrm{csc}}\right.$ ) of $4.7 \times 10^{8}, 4.5 \times 10^{8}$, and $7.7 \times 10^{8} \mathrm{Am}^{-2}$, respectively, at $4.2 \mathrm{~K}$ and $7.5 \mathrm{~T}$. [We assume in this paper that the minimum quench energy (MQE) and $E$ provide consistent measures of conductor stability.]

In this experiment electrical heaters bonded to the conductor surface are pulsed to provide the initial perturbation. Losses to the adjacent epoxy potting are not negligible and cannot be assumed constant for the three conductors. It is, therefore, not possible to measure the MQE reliably. More importantly, K. Ishibashi et al. ${ }^{l}$ show that the critical temperature profile generated by applying the MQE to a given conductor is not necessarily the steady-state profile given by the MPZ theory. ${ }^{2}$ Rather, the critical profile and the value of the MQE depend upon the spatial and temporal distribution of the initial disturbance. But, Ishibashi et al. do report that for perturbations of small extent $(\Delta \mathrm{x} \leqslant 2 \mathrm{~cm})$ and short duration $(\Delta \mathrm{t} \leqslant 2 \mathrm{~ms})$, the critical profile closely approximates the MPZ profile and remains stable for a significant period of time. It is only for larger $\Delta x$ or $\Delta t$ that the critical profile differs significantly from, the MPZ profile. This suggests the following experimental procedure:

(1): Apply heat pulses having identical, small $\Delta x$ and $\Delta t$ ( $\Delta t=1 \mathrm{ms,}$ $\Delta x=1 \mathrm{~cm})$. Vary only the intensity of the heat pulse.

(2) Experimentally determine which heat pulse generates a nearly steady critical profile.

(3) Use the measured voltage drop across this critical profile to determine $\mathrm{E}$. 


\section{BASIC EQUATIONS}

If we assume constant thermophysical properties, we can derive simple, closed formulas of considerable heuristic value for the voltage, energy, and central temperature of MPZs. We begin with a steady-state heat balance for a unit length of composite superconductor:

$$
\frac{d}{d x}\left(k \frac{d T}{d x}\right)+Q_{J}-\frac{h P}{A}\left(T-T_{b}\right)=0 .
$$

(All symbols are defined in a list at the end of the paper.) We reduce the order of this differential equation by using the substitution of Maddock, James, and Norris, ${ }^{3} s=k(d T / d x)$ :

$$
s \frac{d s}{d T}+k\left[Q_{J}-\frac{h P}{A}\left(T-T_{b}\right)\right]=0 .
$$

If we introduce dimensionless variables, Eq. (2) becomes

$$
y \frac{d y}{d \tau}+\alpha i^{2} g(\tau)-\tau=0
$$

where $g(\tau)$ is the tunction of Keilin et al..$^{\prime}$ and Maddóck ét al. $:^{8}$

$$
g(\tau)= \begin{cases}0 & 1-i \geqslant \tau \\ (\tau+i-1) / i & 1-i<\tau<1 . \\ 1 & \tau \geqslant 1 .\end{cases}
$$

The function $g(\tau)$ gives the fraction of the current flowing in the copper as a function of temperature. Use of this function is equivalent to assuming a linear relation between temperature and critical current. In the range of temperatures $\tau<1-i$, the conductor is superconducting; in the range $1-i<\tau<1$, it is current-sharing; and, for $\tau>1$, it is normal. 
3. CONNECTION BETWEEN MPZ VOLTAGE AND ENERGY

The MPZ energy is given by

$$
\begin{aligned}
E & =\int_{-\infty}^{\infty} S\left(T-T_{b}\right) A d x=2 \int_{T_{b}}^{T_{\max }} \frac{k S\left(T-T_{b}\right) A}{s} d T \\
& =2\left(\frac{k A}{h P}\right)^{1 / 2} S\left(T_{c r}-T_{b}\right) A \int_{0}^{\tau_{0}} \frac{\tau d \tau}{y} .
\end{aligned}
$$

The voltage $d V$ across an element $d x$ of the normal zone is equal to the resistance of the copper path $\rho \mathrm{dx} / \mathrm{fA}$ times the current $\operatorname{Ig}(\tau)$ flowing in the copper. Thus,

$$
\begin{aligned}
V & =\int_{-\infty}^{\infty} \frac{\rho \operatorname{Ig}(\tau)}{f A} d x=2 \int_{0}^{T_{\max }} \frac{I \rho k}{s f A} g(\tau) d T \\
& =2\left(\frac{k A}{h P}\right)^{1 / 2} \frac{I \rho}{f A} \int_{0}^{\tau_{0}} \frac{g(\tau)}{y} d \tau
\end{aligned}
$$

If we divide Eq. (3) by $y$ and integrate between $\tau=0$ and $\tau=\tau_{0}$, we find

$$
\alpha i^{2} \int_{0}^{\tau_{0}} \frac{g(\tau)}{y} d \tau=\int_{0}^{\tau_{0}} \frac{\tau}{y} d \tau,
$$

since $y=0$ at both $\tau=0$ and $\tau=\tau_{0}$. From (7), (6b), and (5b), it follows that

$$
\mathrm{E}=\frac{\mathrm{VIAS}}{\mathrm{Ph}}
$$


This relation connects the MPZ energy (E) with the MPZ voltage (V), a conveniently measured quantity. It is interesting that relation ( 8 ) has. been obtained without solving the differential Eq. (3) and that it applies independently of the precise form of the function $g(\tau)$. It does, however, depend on the assumption of constant thermophysical properties. 


\section{CALCULATION OF THE MPZ}

If we integrate Eq. (3) as it stands from 0 to $\tau_{0}$, we find

$$
\int_{0}^{\tau_{0}}\left[\alpha i^{2} g(\tau)-\tau\right] d \tau=0,
$$

which requires the equality of the two shaded areas shown in Fig. 1.

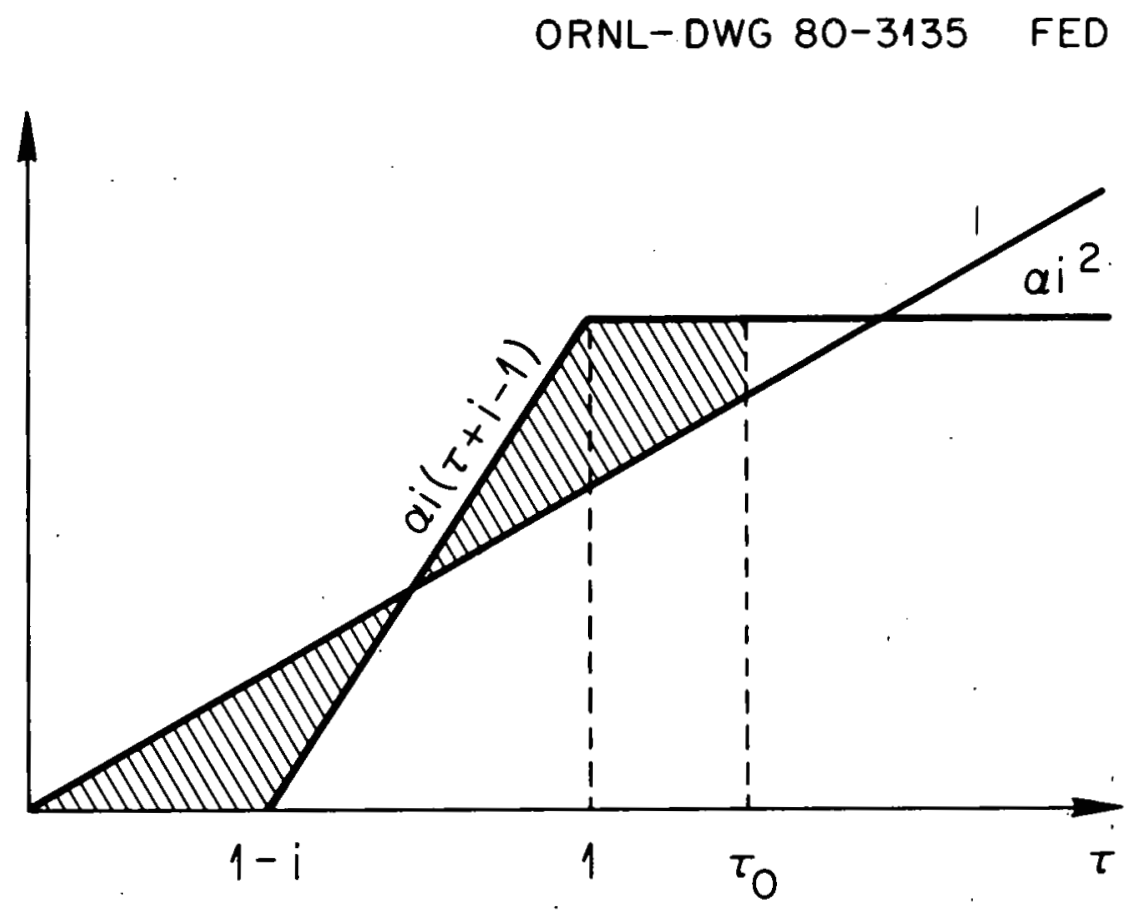

Fig. 1. A sketch illustrating the determination of the maximum temperature of the minimum propagating zone with the equal-area criterion.

If $\tau_{0}<1$ (small MPZs, low, stability), then it can be shown easily from Fig. 1 that

$$
\tau_{0}=(1-i) \frac{\sqrt{\alpha i}}{\sqrt{\alpha i}-1} .
$$


In terms of $\alpha$ and $i$, the condition $\tau_{0}<1$ for (9) becomes $\alpha i^{3}>1$. When $\tau_{0}<1$, Eq. (3) can be solved to give

$$
\begin{aligned}
& y=\tau \quad 0<\tau<1-i, \\
& y=\left[\tau^{2}-\alpha i(\tau+i-1)^{2}\right]^{1 / 2} \quad 1-i<\tau<\tau_{0} .
\end{aligned}
$$

Thus,

$$
\varepsilon=\int_{0}^{\tau_{0}} \frac{\tau}{y} \mathrm{~d} \tau=(1-i)+\int_{1-i}^{\tau_{0}} \frac{\tau d \tau}{\left[\tau^{2}-\alpha i(\tau+i-1)^{2}\right]^{1 / 2}},
$$

or, after some tedious computation,

$$
\frac{\varepsilon}{1-i}=\frac{\alpha i}{\alpha i-1}\left[1+\frac{\frac{\pi}{2}+\arcsin \left(\frac{1}{\sqrt{\alpha i}}\right)}{\sqrt{\alpha i-1}}\right] \text {. }
$$

Using Eq. (11b), we can calculate contours of constant dimensionless MPZ energy $(\varepsilon)$ in the $\alpha-i$ plane. First, we plot the right-hand side of Eq. (11b) as a function of $\alpha i$. Then, we fix $\varepsilon$ and choose a value of $i$. We can determine $\alpha i$ and, thus, $\alpha$ from the value of $\varepsilon /(1-i)$, which we can now calculate, and from the plot made in the first step. Figure 2 shows such contours for $\varepsilon=0.25,0.50$, and 1.0 . Figure 2 also shows the locus $C_{1}: \alpha i^{2}=2$ - $i$ that separates the cryostable from the merastable part of the $\alpha-i$ plane and the locus $c_{2}: \alpha i^{3}=1$. (The locus $C_{0}: \alpha i^{2}=1$ separates full recovery from cold-end recovery.) The contours for $\varepsilon=0.25,0.50$, and 1.0 all lie to the right of $\mathrm{C}_{2}$ so that the condition $\alpha i^{3}>1$ is fulfilled along them, as it should be.

The locus $C_{1}$ corresponds to $\varepsilon=\infty$. When $\varepsilon$ is large, we expect $\alpha i^{3}$ to be $<1$ and $\tau_{0}$ to be $>1$. In fact, for very large $\varepsilon$, $\tau_{0}$ will be close to the equal-area value it would have on $C_{l}$, namely, $\tau_{0}=\alpha i^{2}=$ $2-i>1$. In such a case, we can avoid the labor involved in calculating $\varepsilon$ exactly by replacing the three-part heat generation curve given in Eq. (4) by a two-part heat generation curve, 


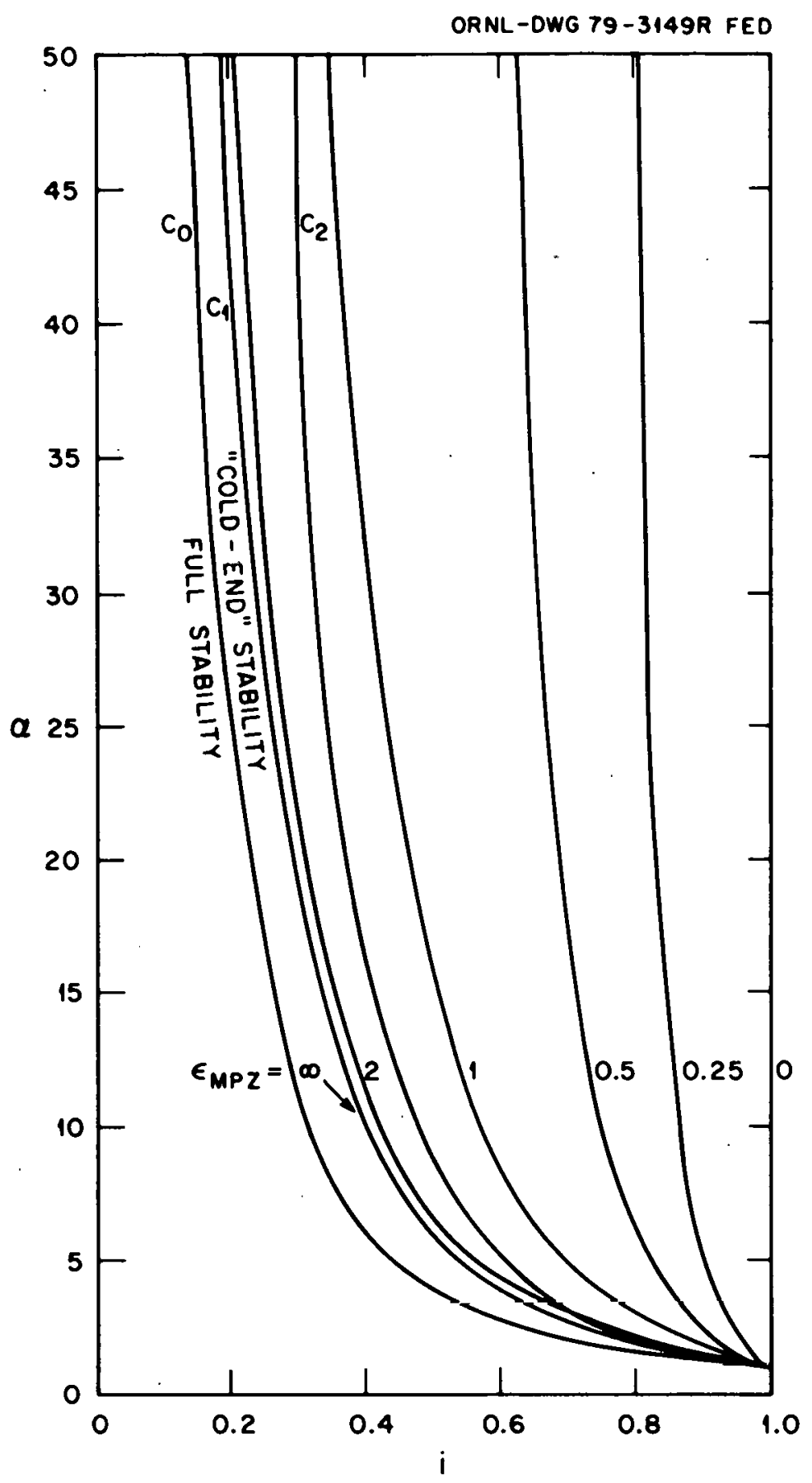

Fig. 2. Contours of the dimensionless MPZ energy $\varepsilon$ in the $\alpha-i$ plane. The locus $C_{l}$ separates the cryostable from the metastable parts of the plane and the locus $C_{0}$ separates full recovery from cold-end recovery. The locus $\mathrm{C}_{2}$ defines the region of validity of the approximate formula (14) for $\varepsilon$ and is discussed in Sect. 4. 


$$
g(\tau)=\left\{\begin{array}{ll}
0 & \tau<1-\frac{i}{2} \\
1 & \tau>1-\frac{i}{2}
\end{array},\right.
$$

in which a sudden transition occurs at the equal-area temperature 5 $\tau=1-i / 2$. Then,

$$
\begin{aligned}
& y=\tau \quad 0<\tau<1-\frac{i}{2}, \\
& y=\left[\tau^{2}-2^{\prime} \alpha i^{2}\left(\tau+\frac{i}{2}-1\right)\right]^{1 / 2}, 1-\frac{i}{2}<\tau,
\end{aligned}
$$

and

$$
\tau_{0}=\alpha i^{2}\left(1-\sqrt{1-\frac{2-i}{\alpha i^{2}}}\right) .
$$

Integrating, we find

$$
\begin{aligned}
\varepsilon & =\int_{0}^{\tau_{0}} \frac{\tau}{y} \mathrm{~d} \tau=1-\frac{i}{2}+\int_{1-\frac{i}{2}}^{\tau_{0}} \frac{\tau d \tau}{\left[\tau^{2}-2 \alpha i^{2}\left(\tau+\frac{i}{2}-1\right)\right]^{1 / 2}} \\
& =\alpha i^{2} \ln \left(1-\frac{2-i}{\alpha i^{2}}\right)^{-1 / 2}
\end{aligned}
$$

Table 1 shows: a comparison of Eqs. (11b) and (14b) along the boundary curve $c_{2}: \alpha i^{3}=1$. Agreement is quite good except for $i$ near 1 , where the curves $C_{2}$ and $C_{1}$ are very close together. Thus, we expect Eq. (14b) to be sufficiently reliable to sketch the general trend of higher $\varepsilon$ contours in the $\alpha-i$ plane. Figure 2 shows the contour for $\varepsilon=2$ calculated using Eq. (14b). 
Table 1. Comparison of Eqs. (11b) and (14b) along $\alpha i^{3}=1$

\begin{tabular}{cccc}
\hline & \multicolumn{3}{c}{$\varepsilon$} \\
\cline { 2 - 3 } & Eq. (11b) & Eq. $(14 \mathrm{~b})$ \\
\hline 0.2 & 1.13 & 1.12 \\
0.3 & 1.22 & 1.19 \\
0.4 & 1.33, & 1.28 \\
0.5 & 1.47 & 1.39 \\
0.6 & 1.66 & 1.53 \\
0.7 & 1.94 & 1.72 \\
0.8 & 2.41 & 2.01 \\
0.9 & 3.45 & 2.56 \\
\hline
\end{tabular}

1, 
5. USE OF THE $\varepsilon$ CONTOURS TO SELECT A Cu/SC RATIO 6

We can use the $\varepsilon$ contours in Fig. 2 to determine the $\mathrm{Cu} / \mathrm{SC}$ ratio of metastable conductors. Consider, for example, a candidate conductor intended for service at $8 \mathrm{~T}, 4.2 \mathrm{~K}$, and an overall current density of $9 \times 10^{7} \mathrm{Am}^{-2}$. The conductor is to be a composite of NbTi, whose critical current density is $5.6 \times 10^{8} \mathrm{Am}^{-2}$ at $8 \mathrm{~T}$ and $4.2 \mathrm{~K}$, and copper, whose residual resistivity ratio is 160 . With these data fixed,

$$
\alpha=\frac{1.2 \times 10^{8}}{(\mathrm{Ph} / \mathrm{A})} \frac{(1-\mathrm{f})^{2}}{\mathrm{f}} \quad\left(\mathrm{Ph} / \mathrm{A} \text { in } \mathrm{Wm}^{-3} \mathrm{~K}^{-1}\right)
$$

and

$$
1=\frac{0.16}{1-\mathrm{f}} \text {, }
$$

where $f$ is the volume fraction of copper in the composite. The quantity $\mathrm{Ph} / \mathrm{A}$ is not usually very well known in the early stages of design, but for the conductor described above, a reasonable range of values is $2 \times 10^{5}$ to $5 \times 10^{6} \mathrm{Wm}^{-3} \mathrm{~K}^{-1}$. Figure 3 shows the loci traced out by Eqs. (15a,b) in the $\alpha-i$ plane as $t$ varies for varlous values of $\mathrm{Fh} / \mathrm{A}$. If we $\mathrm{fix}$ the value of $\mathrm{Ph} / \mathrm{A}$ (take $\mathrm{Ph} / \mathrm{A}=1 \times 10^{6} \mathrm{Wm}^{-3} \mathrm{~K}^{-1}$, for example) and superimpose the $f$ locus on Fig. 2, the intersections of the f locus with the contours of constant $\varepsilon$ give $\varepsilon$ as a function of $f$. When $f=0.84$ $(\mathrm{Cu} / \mathrm{SC}=5.25)$, the operating current equals the critical current, and $\varepsilon=0$. Near the right-hand side of the graph, the f locus cuts the contours of constant $\varepsilon$ steeply so that we start out moving rapidly from $\varepsilon$ contour to $\varepsilon$ contour as $f$ decreases. However, as $f$ continues to decrease, the $t$ locus becomes nearly parallel to the contouro of culistant $\varepsilon$, and a point is reached at which further reduction of $f$ brings little increase in stability. In the present example, the point of diminishing recurns occurs at $i \sim 0.6$, for which $f=0.73(\mathrm{Cu} / \mathrm{SC}=2.7 n)$. When $\mathrm{Cu} / \mathrm{SC}=5(\mathrm{f}=0.83,1=0.96), \varepsilon$ is only one-sixth as large as $i t$ is for $\mathrm{Cu} / \mathrm{SC}=2.7$, so the lower ratio is preferable. 


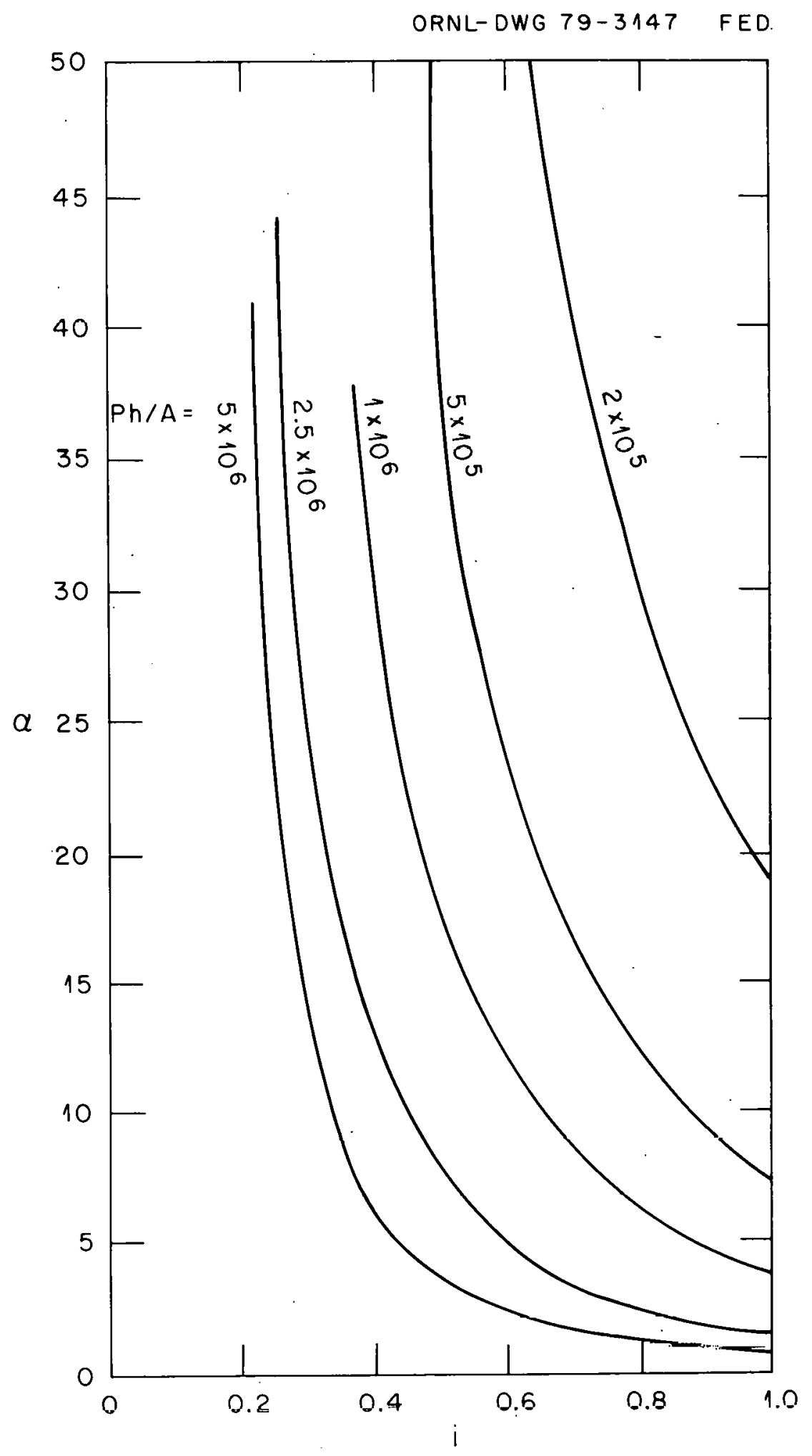

Fig. 3. The loci traced out by Eqs. (15) in the $\alpha-i$ plane as the copper fraction $f$ varies, for several values of $\mathrm{Ph} / \mathrm{A}$. 
We get the same conclusion no matter which $f$ locus we consider up to values of $\mathrm{Ph} / \mathrm{A}=5 \times 10^{6} \mathrm{Wm}^{-3} \mathrm{~K}^{-1}$. For this value of $\mathrm{Ph} / \mathrm{A}$, it is possible to achieve cryostability (both cold-end and full stability). Paradoxically, to achieve cryostability when $\mathrm{Ph} / \mathrm{A}$ is large, we need large $\mathrm{Cu} / \mathrm{SC}$ ratios. However, for metastable conductors with smaller $\mathrm{Ph} / \mathrm{A}$, we prefer low $\mathrm{Cu} / \mathrm{SC}$ ratios. 


\section{SAMPLE PREPARATION}

To obtain test conductors having nearly identical geometries and different values of $\mathrm{f}$, three NbTi/Cu composite conductors were soldered into U-shaped copper channels formed from a $5.6-\mathrm{mm} \times 0.56-\mathrm{mm}$ copper strip. Data for the test conductors are provided in Table 2. A photograph of one of the finished conductor cross sections is shown in Fig. 4. The conductor was wound under tension in a helical groove machined in a G-10 fiberglass cylinder and potted in place with Emerson and Cummings 2850FT Stycast epoxy with one face exposed to the helium bath (see Fig. 5). The external magnetic field was applied parallel to the axis of the fiberglass cylinder.

Strain gauges $(R=120 \Omega$ ) bonded to the side of the conductor in contact with the fiberglass cylinder were used as heaters (see Fig: 5). A 1-cm heater was positioned at the center of each 3-m test conductor. Seven voltage taps were soldered to the conductor at various locations. The voltage'tap leads were co-wound with the conductor in the helical groove of the sample holder in order to reduce inductive pirkkup.

A schematic representation of the instrumentation is shown in Fig. 6 . 
Table 2. Conductor specifications

\begin{tabular}{|c|c|c|c|c|c|c|c|c|}
\hline \multirow[b]{2}{*}{ Sample } & \multicolumn{3}{|c|}{ Initial conductor } & \multicolumn{2}{|c|}{ Test conductor } & \multicolumn{3}{|c|}{$p(. \mathrm{zI})$ and $\mathrm{J}_{\mathrm{csc}}\left(\mathrm{Am}^{-2}\right)$} \\
\hline & $\begin{array}{l}\text { Dimensions } \\
(\mathrm{mm} \times \mathrm{mn})\end{array}$ & $\mathrm{Cu} / \mathrm{SC}$ & "Filaments & Tctal area $\left(\mathrm{m}^{2}\right)$ & $\mathrm{Cu} / \mathrm{SC}$ & $B=5.0 \Xi$ & $7.0 \mathrm{~T}$ & $7.5 \mathrm{~T}$ \\
\hline 1 & $2.54 \times 1.27$ & 2.55 & 18 & $6.2 \times 10^{-6}$ & 5.35 & $\begin{array}{l}J_{c s c}=7.8 \times 10^{8} \\
\rho=3.8 \times 10^{-13}\end{array}$ & $\begin{array}{l}J_{c s c}=5.0 \times 10^{8} \\
J=4.1 \times 10^{-10}\end{array}$ & $\begin{array}{l}J_{c s c}=4.7 \times 10^{8} \\
\rho=4.4 \times 10^{-10}\end{array}$ \\
\hline 2 & $2.54 \times=.27$ & 2.19 & 18 & $6.2 \times 10^{-6}$ & 5.15 & $\begin{array}{l}\mathrm{J}_{\mathrm{csc}}=7.4 \times 1 \mathrm{~J}^{8} \\
\rho=3.8 \times 10^{-10}\end{array}$ & $\begin{array}{l}J_{c s c}=5.3 \times 10^{8} \\
2=4.2 \times 10^{-10}\end{array}$ & $\begin{array}{l}J_{c s c}=4.5 \times 10^{8} \\
D=4.4 \times 10^{-10}\end{array}$ \\
\hline 3 & $2.49 \times=.24$ & 1.36 & 1530 & $6.1 \times 10^{-6}$ & 3.55 & $\begin{array}{l}J_{c s c}=1.2 \times 1 \mathrm{j}^{9} \\
\rho=3.9 \times 10^{-10}\end{array}$ & $\begin{array}{l}J_{c s c}=9.1 \times 10^{8} \\
\rho=4.5 \times 10^{-10}\end{array}$ & $\begin{array}{l}J_{\text {csc }}=7.7 \times 10^{8} \\
\rho=4.7 \times 10^{-10}\end{array}$ \\
\hline
\end{tabular}




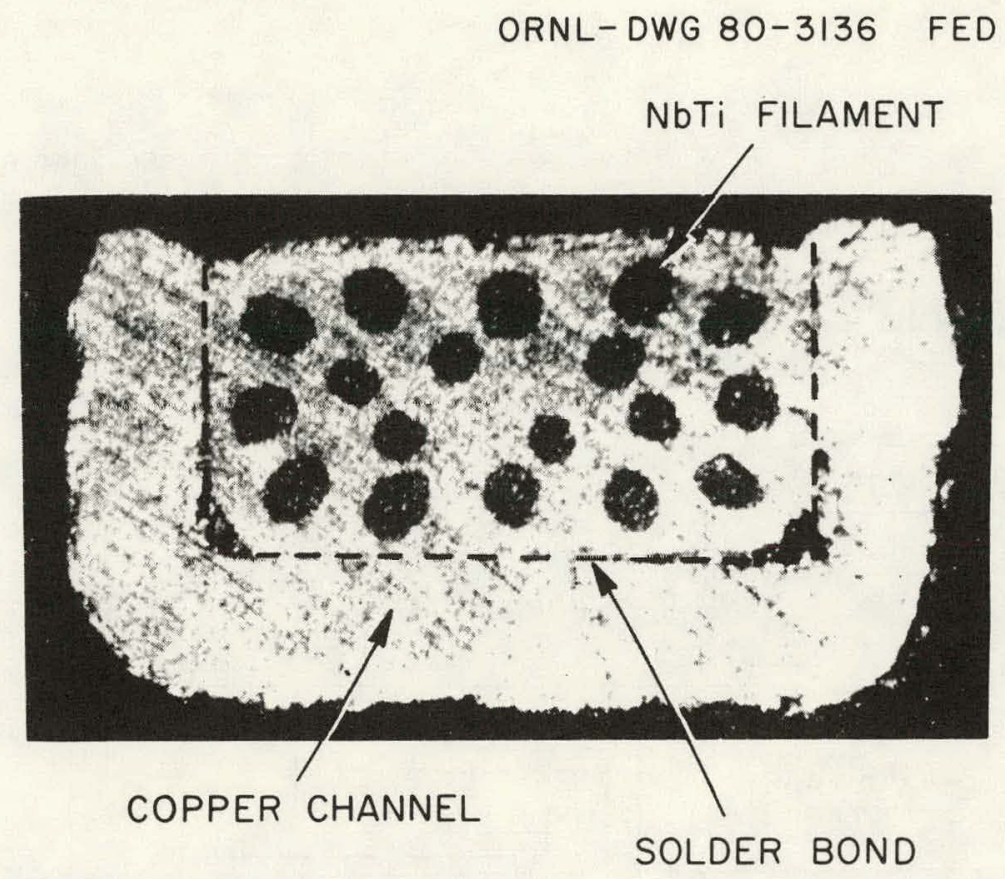

Fig. 4. A photograph of one of the finished conductor cross sections.

ORNL-DWG 80-3137 FED
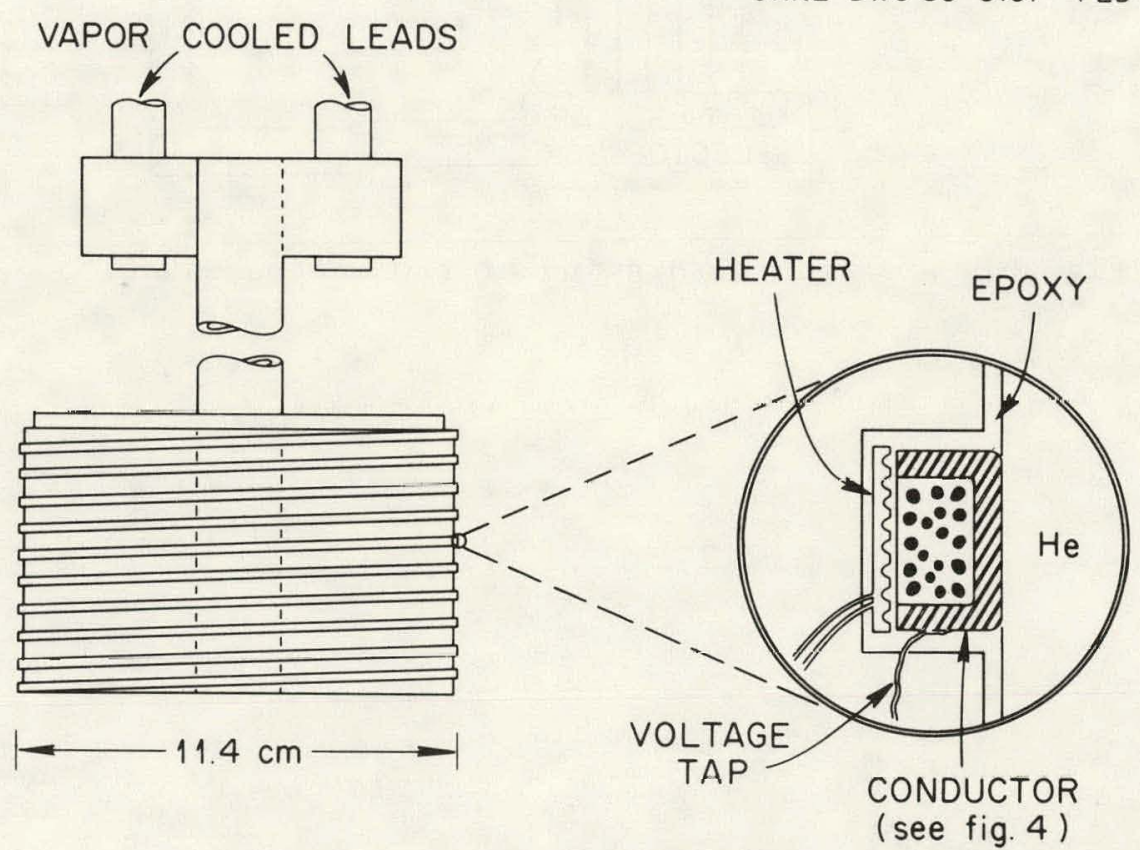

Fig. 5. A sketch of the fiberglass cylinder showing the location of the heater, the conductor, and the epoxy potting. 

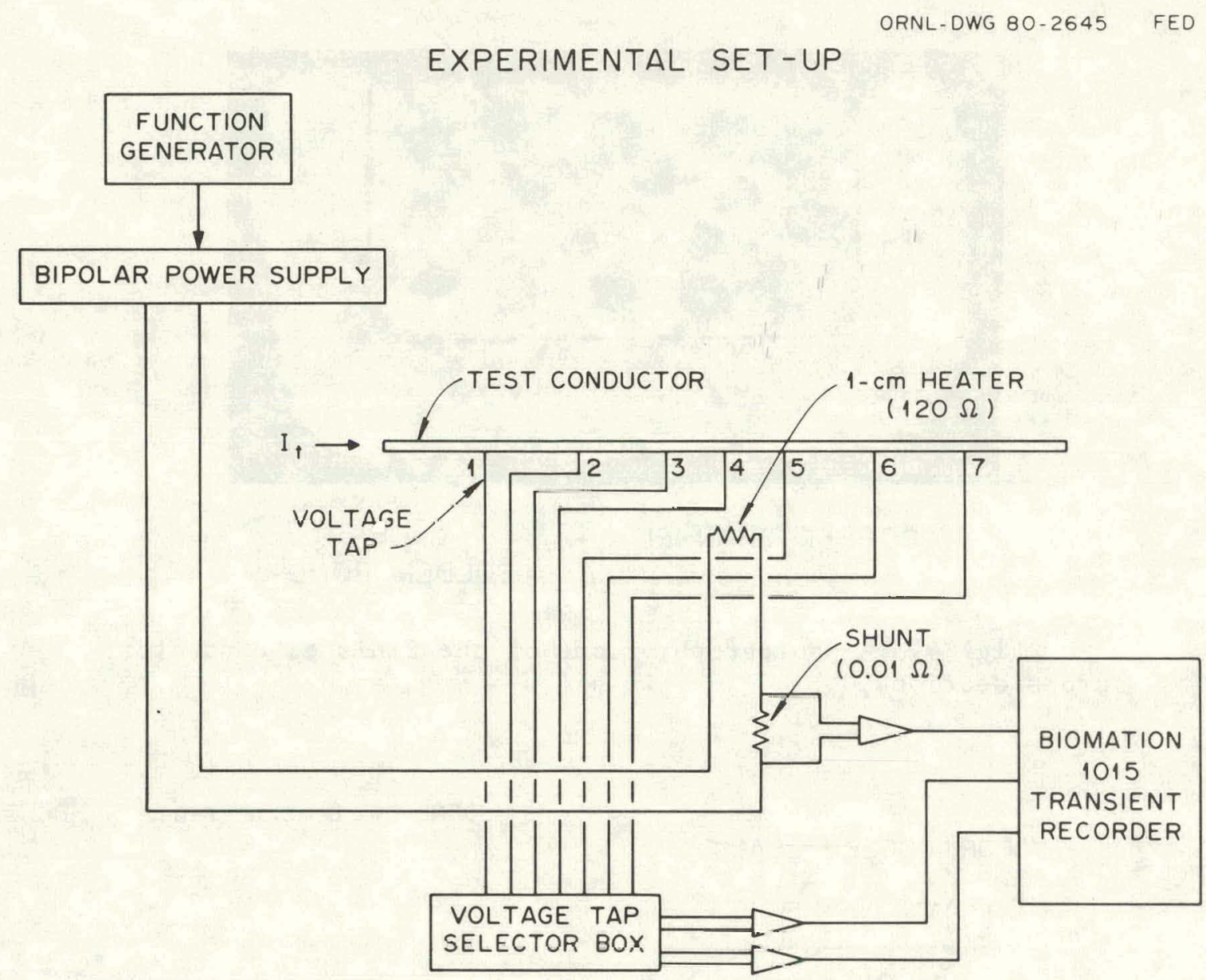

Fig. 6. A schematic drawing of the instrumentation. 


\section{PROCEDURE}

The heater was energized with 2 -ms square pulses of increasing power until the conductor just quenched. For slight changes in energy input about this point, temperature profiles of considerably different time durations developed; we assume that a nearly constant voltage drop is indicative of a nearly steady temperature profile. In Fig. 7 the voltage drops are plotted across the longest lasting zones we could make as a function of transport current for three magnetic fields. Appended to representative data points are the time durations over which the voltages were steady. Figures $8 \mathrm{a}$ and $8 \mathrm{~b}$ are oscilloscope traces of representative voltage drops as functions of time: traces $8 \mathrm{a}$ and $8 \mathrm{~b}$ correspond to $I=400 \mathrm{~A}$ and $I=575 \mathrm{~A}$, respectively (sample $\left.\right|^{3}$, $B=7.5 \mathrm{~T})$. Because of its long duration, trace $8 \mathrm{a}$ probably corresponds to a temperature profile approximating the MPZ profile, but trace $8 \mathrm{~b}$ probably does not.

We also measured propagation velocities for the three conductors at various magnetic fields and transport currents, which are plotted in Fig. 9. Extrapolation of these curves to $v=0$ at fixed $B$ gives the minimum propagating currents $\left(\mathrm{I}_{\mathrm{MP}}\right)$. 


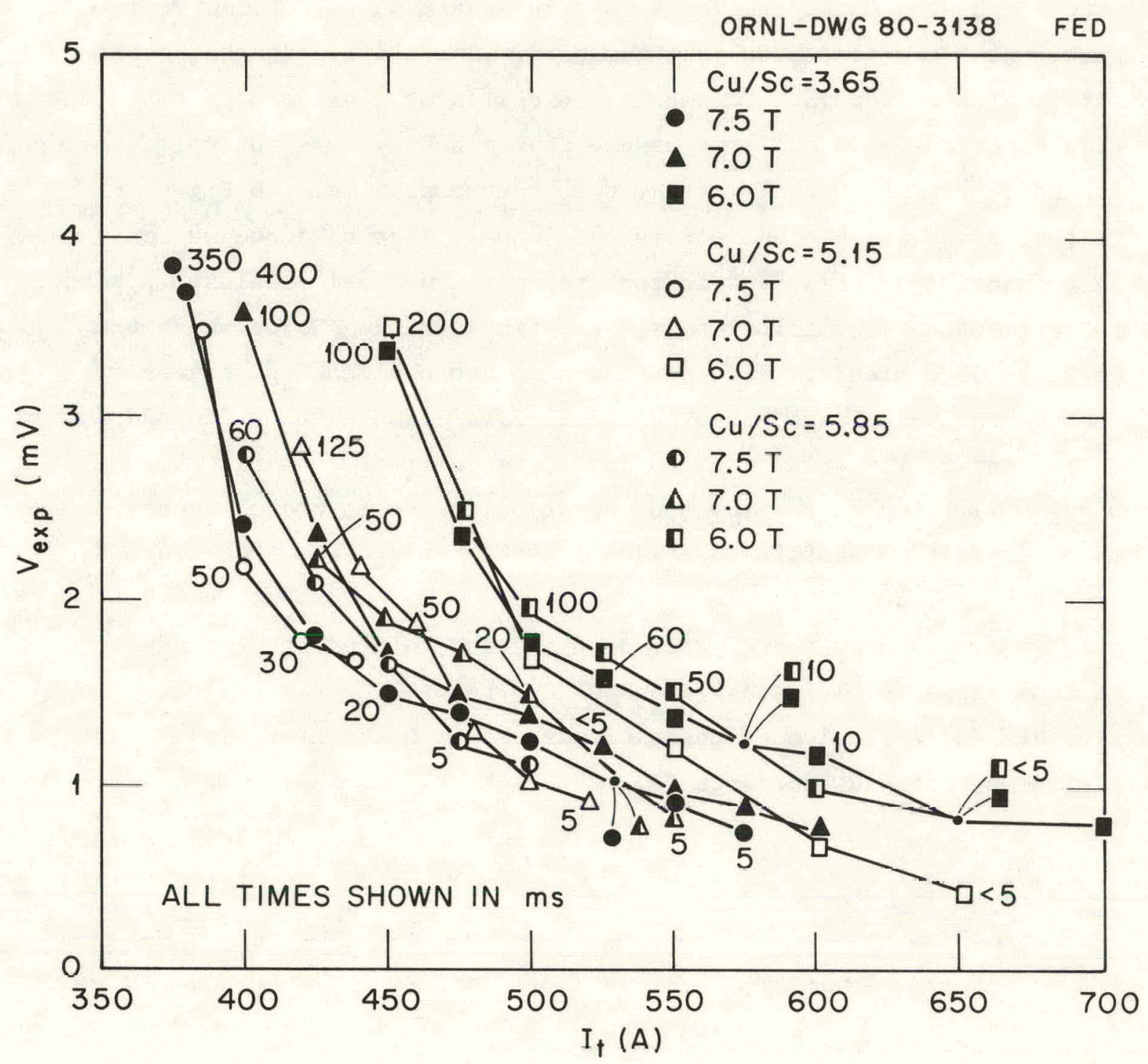

Fig. 7. The voltages across long-lasting normal zones. The numbers attached to the points are the durations, in $\mathrm{ms}$, of the voltages. 
ORNL-DWG $80-2649$ RED
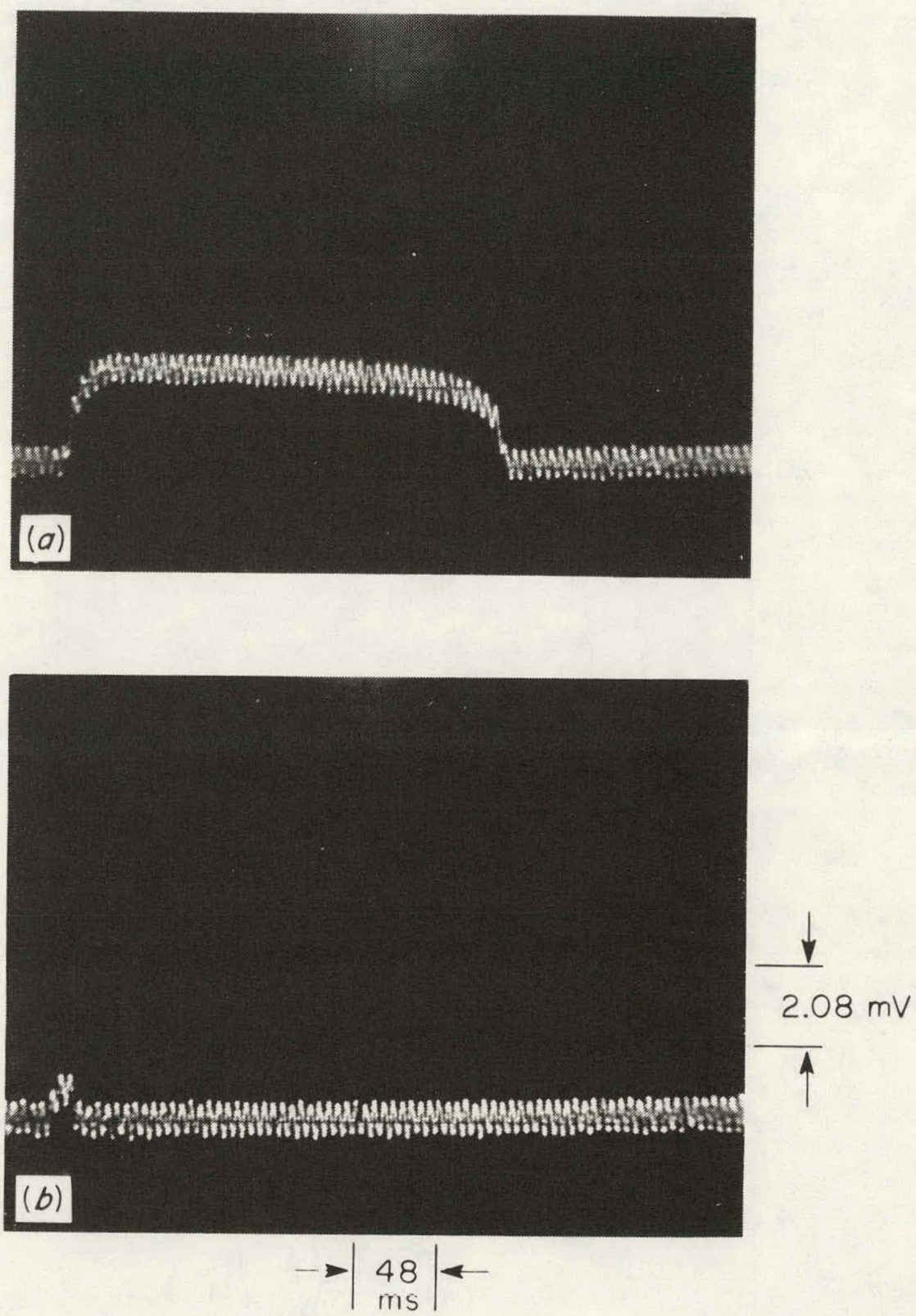

Fig. 8. Typical oscilloscope traces of the voltage across the normal zone as a funciton of time. 


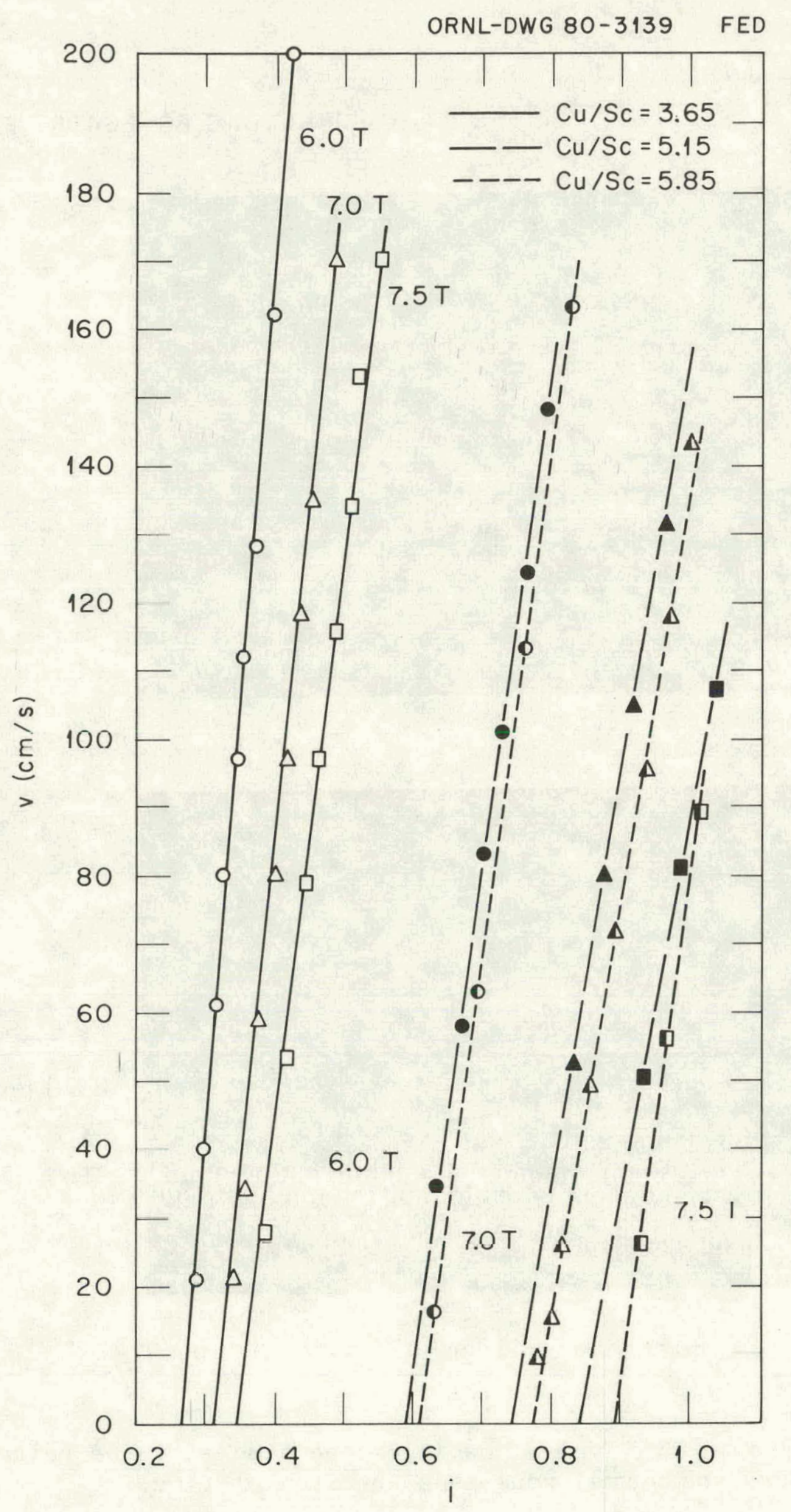

Fig. 9. The propagation velocity for each of the three conductors as a function of field and dimensionless current. 


\section{DISCUSSION}

By assuming a constant heat transfer coefficient, one can apply the equal-area criterion for stability to obtain

$$
\alpha=\frac{2-i_{M P}}{, i_{M P}^{2}} \text {, }
$$

and, then, obtain $h$ from the definition of $\alpha$,

$$
\alpha=\frac{\rho I_{c r}^{2}}{\operatorname{fAPh}\left(T_{c r}-T_{b}\right)} \text {. }
$$

$\mathrm{T}_{\mathrm{cr}}$ is closely given by $\mathrm{T}_{\mathrm{cr}}=9.09-0.439 \mathrm{~B}$ (see Ref. 7) for $\mathrm{Nb}-46 \% \mathrm{Ti}$ (B in $T, T_{c r}$ in $K$ ). By comparing Eqs. (6b) and (11a), we see that

$$
\mathrm{V}=2\left(\frac{\mathrm{kA}}{\mathrm{hP}}\right)^{1 / 2} \frac{\mathrm{I} \rho}{\mathrm{fA}} \varepsilon
$$

Using Eq. (11b) for the range $\alpha i^{3}>1$ and Eq. (14b) for $\alpha i^{3}<1$, we can calculate $V$. We use a value of $k$ obtained by applying the WiedemannFranz Law 8 at the average of $\mathrm{T}_{\max }$ and $\mathrm{T}_{\mathrm{b}}$ :

$$
k=\frac{2.45 \times 10^{-8} \mathrm{~V}^{2} \mathrm{~K}^{-2}}{\rho}\left(\frac{\mathrm{T}_{\mathrm{b}}+\mathrm{T}_{\max }}{2}\right)
$$

$T_{\max }$ is calculated using Eq. (9), where

$$
\tau_{0}=\frac{T_{\max }-T_{b}}{T_{c r}-T_{b}} .
$$

Shown in Fig. 10 is the ratio $\mathrm{V}_{\exp } / \mathrm{V}_{\text {calc }}$ for the test conductors as a function of the dimensionless current $i$. As $i \rightarrow 1, v_{\text {exp }} / v_{\text {calc }}$ becomes 


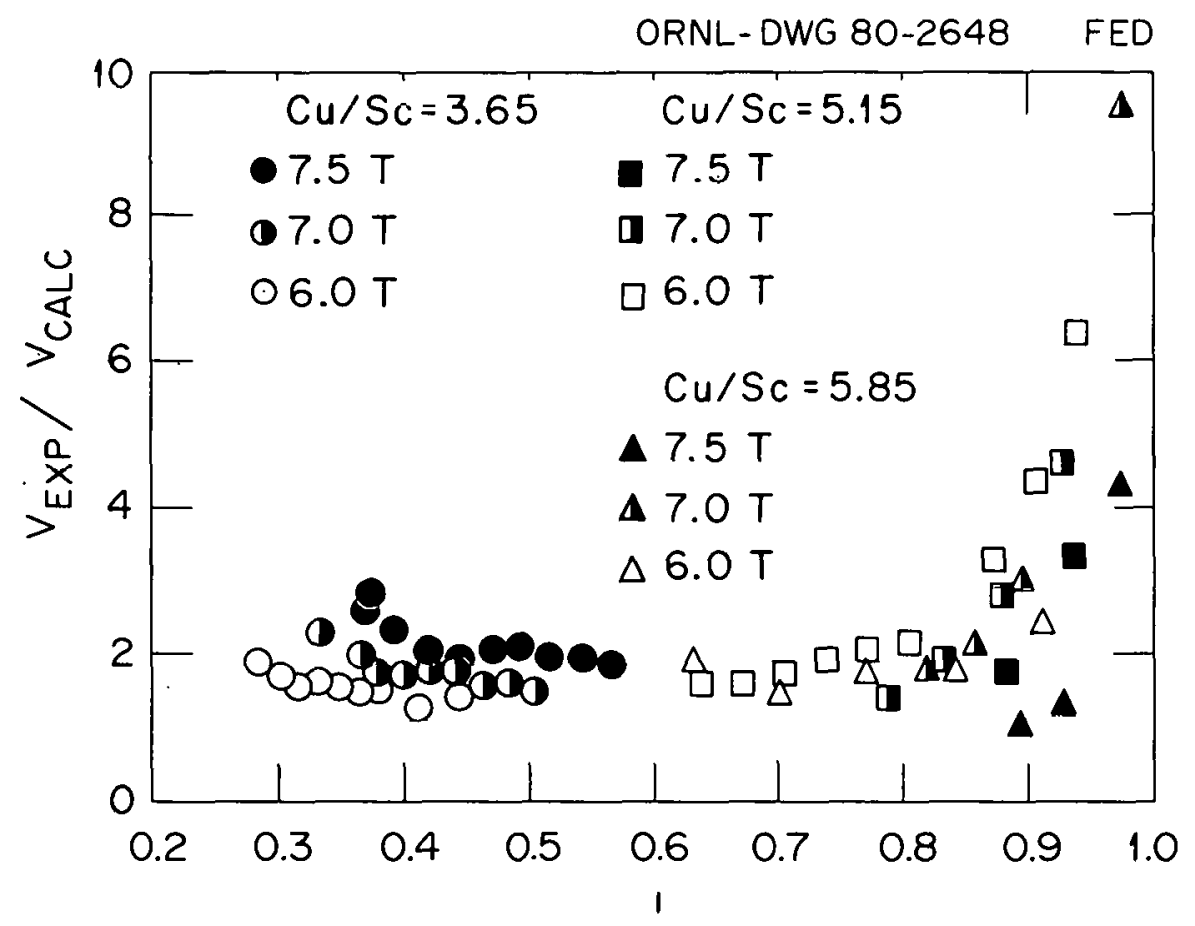

Fig. 10. The ratio of the experimental to the calculated normal zone voltage.

very large, but the experimental values for $V$ at $i \rightarrow 1$ prohahly are not. reliable (see discussion of Fig. $8 b$ in Sect. 7). For $i<0.9, v_{\exp }^{\prime}$ $\mathrm{V}$ calc $\backsim 2$.

The most likely source of error in the theory presented above is the assumption of a constant heat transfer coefficient. Boiling heat transfer coefficients vary greatly with surface conditions and $\Delta T$. A more realistic boiling curve would be a three-part curve like that of Fig. 1la; the corresponding heat transfer coefficient is shown in Fig. 11b. 'The constant value of $h$ used in our simple model should now be replaced by an effective heat transfer coefficient $\vec{h}$ lying somewhere between the extremes shown in Fig. $11 \mathrm{~b}$.

Instead of using the value of $h$ given by Eqs. (16) and (17), we now find the $\bar{h}$ which makes $V_{\text {exp }}=V_{\text {calc }}$. Plots of $\bar{h}$ vs $T_{\max }$ are shown in Fig. 12. In order to further understand the curves of $\bar{h}$, we did three things: 

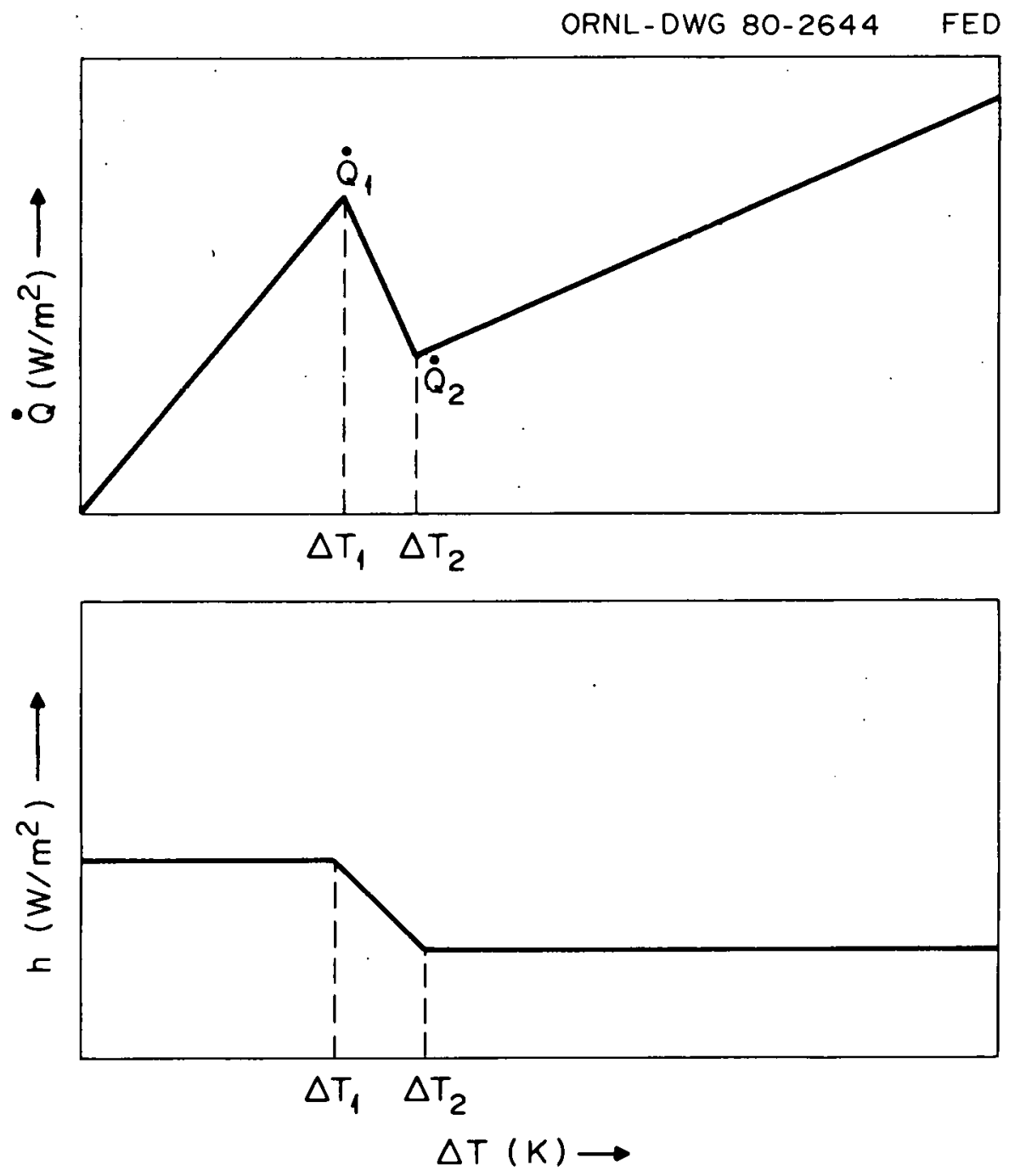

Fig. 11. A sketch of a three-part boiling curve and its associated heat transfer coefficient. 


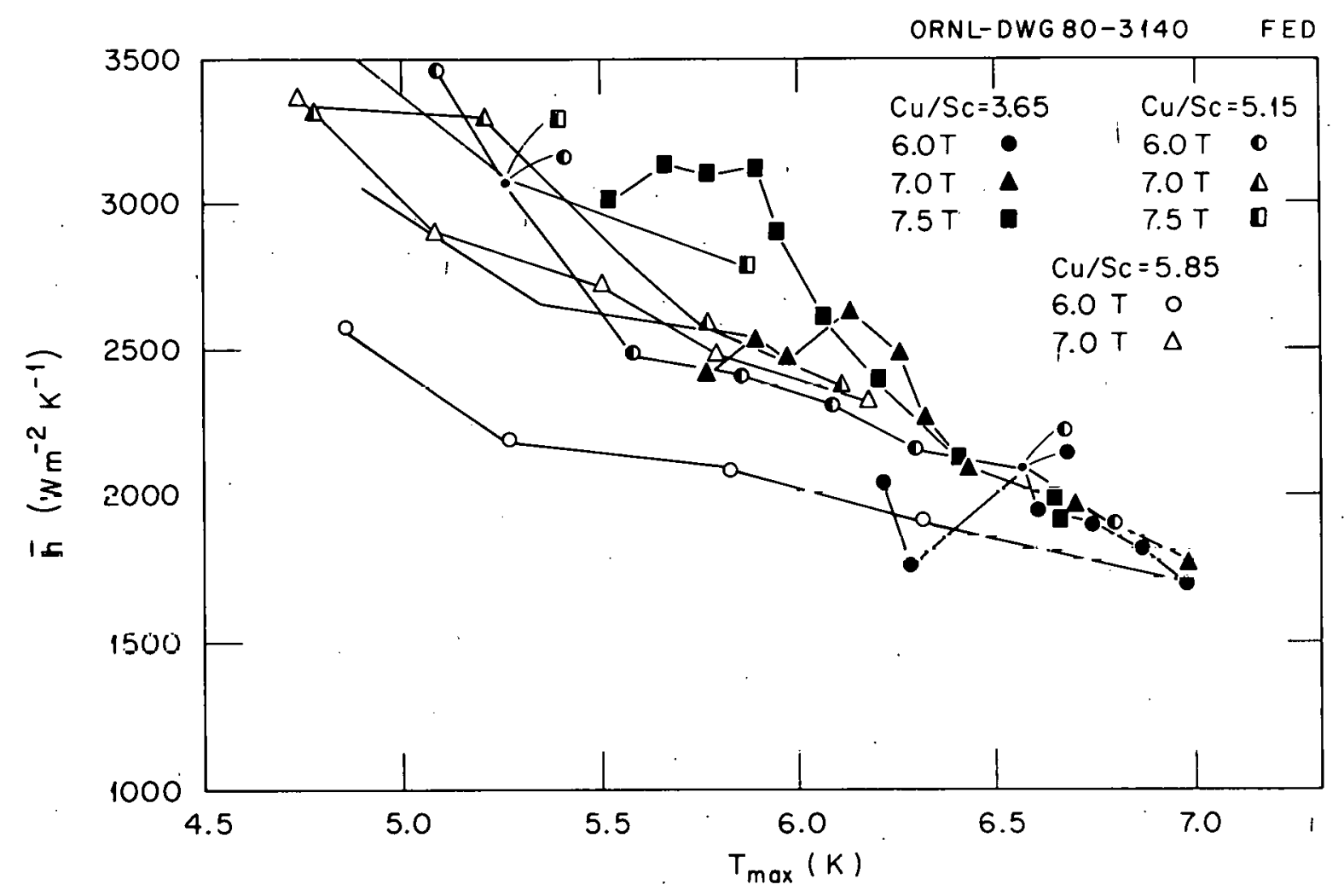

Fig. 12. A plot of the effective heat transfer coefficient $\bar{h}$ versus $\mathrm{T}_{\text {max }}$, the maximum normal zone temperature.

(1) We simulated further experiments on a computer by numerically integrating the heat balance equation [Eq. (1)]. The computer program assumes a three-part boiling curve and variable thermal conductivity (given by the Wiedemann-Franz. Law eva1uated at $T$ ) and gives $V$ and $E$ dixentily.

(2) We used the values of $V$ from step (1) as new data for the simple model, thereby giving $\bar{h}$.

(3) We changed parameters in the three-part boiling curve of step (1) to observe the resultant changes in $\overline{\mathrm{h}}$.

Assuming initially that $\mathrm{T}_{\max }-\mathrm{T}_{\mathrm{b}}>\Delta \mathrm{T}_{2}$, as $\mathrm{T}_{\max }$ decreases, one sees that the weighted average of $h$ increases (see Fig. Ilb). Near $\mathrm{T}_{\max }-\mathrm{T}_{\mathrm{b}}=\Delta \mathrm{T}_{2}$ and $\mathrm{T}_{\max }-\mathrm{T}_{\mathrm{b}}=\Delta \mathrm{T}_{1}$, one would expect changes in $\mathrm{d} \overline{\mathrm{h}} / \mathrm{dT} \mathrm{T}_{\max }$, and for $T_{\max }-T_{b}<\Delta T_{1}$, one would anticipate $\bar{h}=$ constant. The curves 
for $f=0.785$ seem to be consistent with such an analysis. We nearly duplicated the curve of $\bar{h}$ vs $T_{\max }$ for $f=0.785$ and $B=7.5 \mathrm{~T}$ by assuming:

$$
\begin{array}{ll}
\Delta \mathrm{T}_{1}=1.6 \mathrm{~K} & \dot{\mathrm{Q}}_{1}=4800 \mathrm{Wm}^{-2} \\
\Delta \mathrm{T}_{2}=2.0 \mathrm{~K} & \dot{\mathrm{Q}}_{2}=1000 \mathrm{Wm}^{-2}
\end{array}
$$$$
\mathrm{h}_{\mathrm{film}}=560 \mathrm{Wm}^{-2} \mathrm{~K}^{-1}
$$

Plotted in Fig. 13 are simulated and experimental curves of $\bar{h}$ for $\mathrm{f}=0.785$ and $\mathrm{B}=7.5 \mathrm{~T}$, including the values of $\Delta \mathrm{T}_{1}$ and $\Delta \mathrm{T}_{2}$. The slope of $\bar{h}_{\text {simulated }}$ does in fact change at $\Delta T_{1}$ and $\Delta T_{2}$, and $\bar{h}_{1}$, is fairly constant for $\mathrm{T}_{\max }-\mathrm{T}_{\mathrm{b}}<\Delta \mathrm{T}_{1}$.

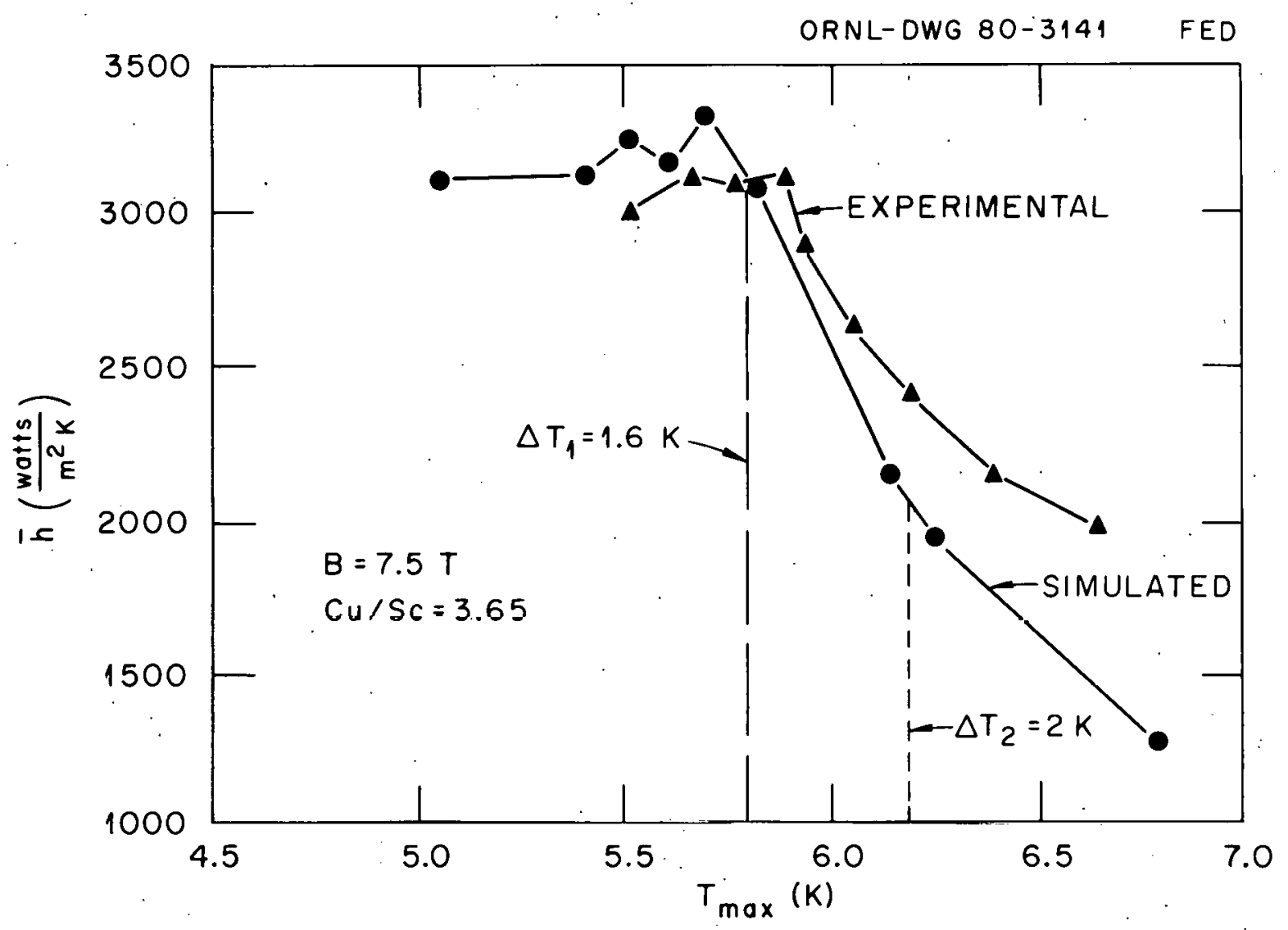

Fig. 13. Simulated and experimental curves of the effective heat transfer coefficient $\bar{h}$ versus $T_{\max }$, the maximum normal zone temperature. 
We used the same boiling curve to generate $\bar{h}$ for the 6.0 - and 7.0-T data, but unlike the experimental $\bar{h}$, the simulated $\bar{h}\left(\mathrm{~T}_{\max }\right)$ is the same for $6.0,7.0$, and $7.5 \mathrm{~T}$.

Using $\bar{h}$, we can calculate $\varepsilon$ for the data points [see Eqs. (11b) and (14b)]. In Fig. 14, representative values of $\varepsilon$ are plotted in the $\alpha-i$ plane; along with theoretical curves of constant $\varepsilon$. Agreement between theory and experiment is good. In Fig. 15, E is plotted as a function of transport current; $\overline{\mathrm{h}}$ is used as the heat transfer coefficient; and $S$ is evaluated at $T_{\max }+T_{b} / 2$ by using the values of the specific heats of $\mathrm{Cu}$ and NbTi given in Ref. 6.

The trend of the MPZ energies shown in Fig. 15 confirms the theoretical expectation that low $\mathrm{Cu} / \mathrm{SC}$ ratios lead to higher stability than high $\mathrm{Cu} / \mathrm{SC}$ ratios. A slight complication arises, however, because samples 1,2 , and 3 differ not only in copper fraction but also in the critical current density $J_{c s c}$ of the NbTi and in the resistivity $\rho$ of the copper (as noted in Table 2). The uncertainty caused by the differences in $J$ and $\rho$ can be dispelled as follows: at a given field and transport current, the three conductors have the parameters $\left(\alpha_{1}, i_{1}\right)$, $\left(\alpha_{2}, i_{2}\right)$, and $\left(\alpha_{3}, i_{3}\right)$. Can we find a copper fraction $f^{\prime}$ such that a conductor with $J_{\text {cscl }}$ and $\rho_{1}$ can have the values $\alpha=\alpha_{3}$ and $i=i_{3}$ ? If we can, then conductor 3 looks like a conductor with the same dimensions and material properties as conductor $I$ but with an effective copper fraction equal to $\mathrm{F}^{\prime}$.

We can in fact do this. If we choose $f^{\prime}=0.670$, we can come within a few percent of the values of $\alpha_{3}$ and $i_{3}$ at all three fields, and if we choose $f^{\prime}=0.845$, we can come within a few percent of $\alpha_{2}$ and $1_{2}$ at all three fields. Thus, using the material properties of sample 1 , the three samples have effective copper fractions of $0.854,0.845$, and 0.670 . On this basis, we expect $E$ of samples 1 and 2 tn he quite close together and that of sample 3 to be substantially larger. This is what is observed, and it confirms our belief that low $\mathrm{Cu} / \mathrm{Sc}$ ratios are best for stability of metastable conductors. 


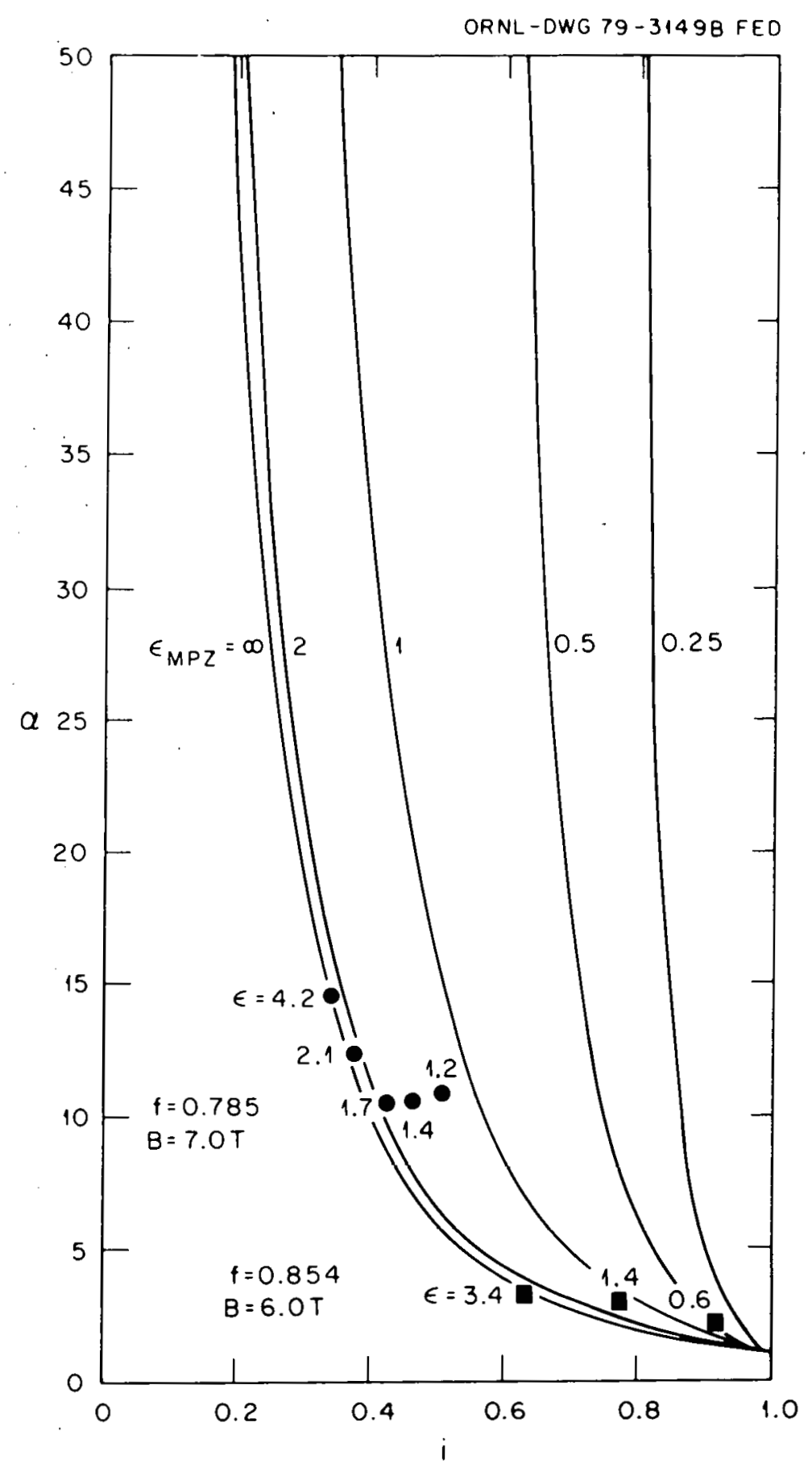

Fig. 14. A plot in the $\alpha-i$ plane of some values of $\varepsilon$ calculated using the effective heat transfer coefficient $\bar{h}$. The curves are the $\varepsilon$ contours from Fig. 2 . 


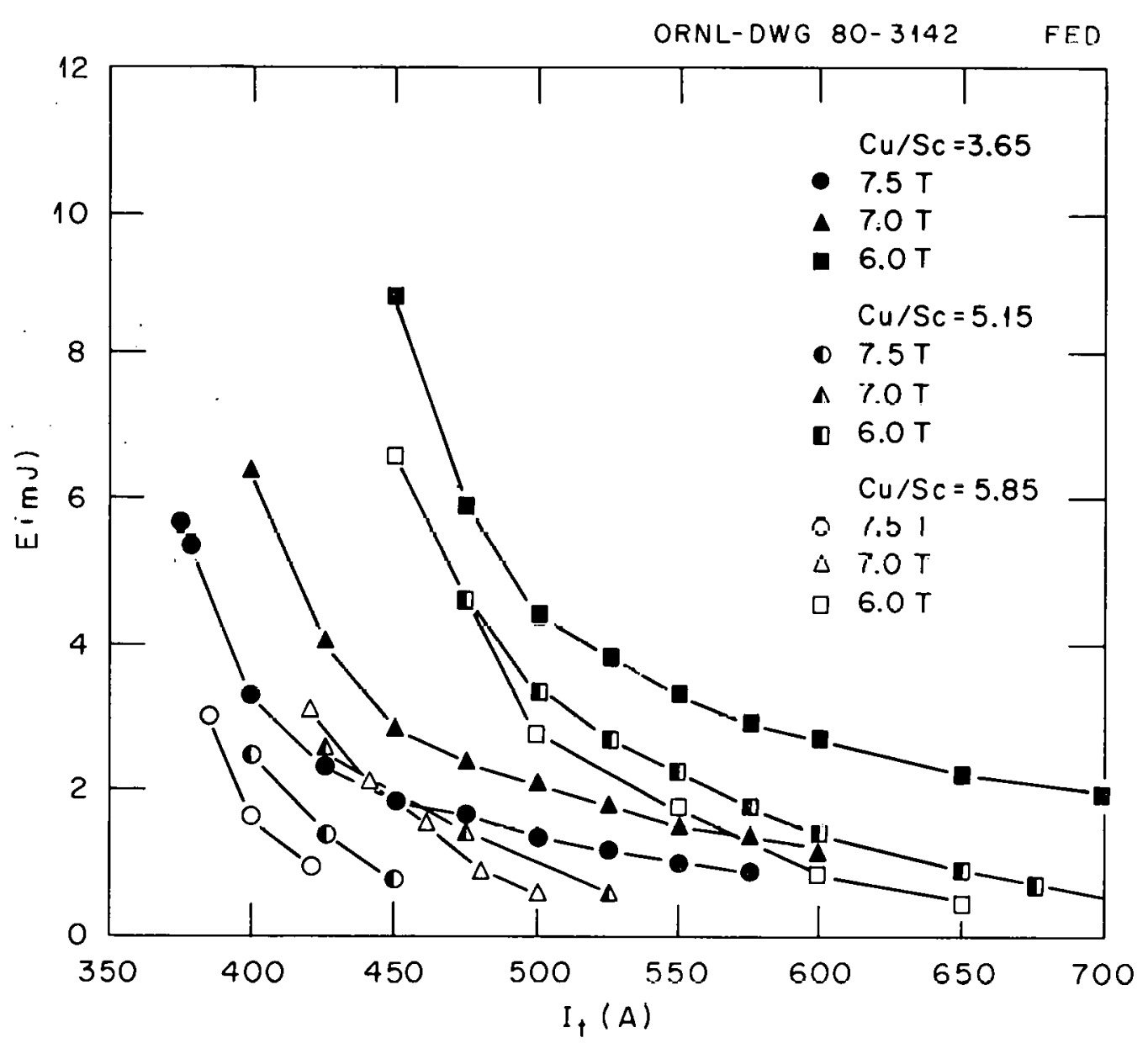

Fig. 15. The energy of the minimum propagating zone as a function of copper fraction, magnetic field, and transport cultell.

\section{ACKNOWLEDGMENTS}

We would like to thank M. S. Lubell for suggesting this problem and to thank J. P. Rudd for his help in preparing the samples. 
SYMBOLS

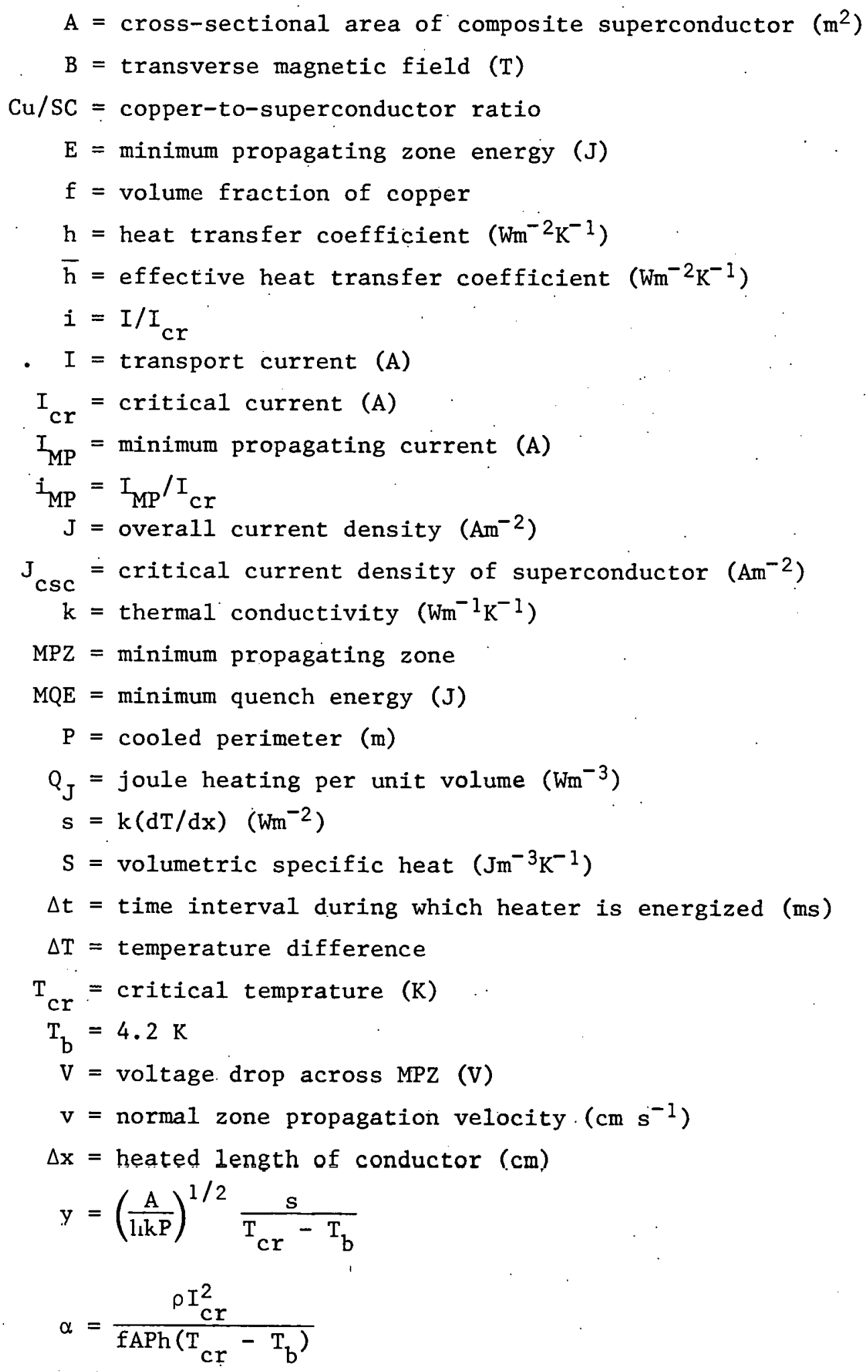




$$
\begin{aligned}
& \varepsilon=\frac{E}{2 A S\left(T_{c r}-T_{b}\right)(A k / P h)^{l / 2}} \\
& \rho=\text { resistivity of copper }(\Omega m)
\end{aligned}
$$$$
\tau=\frac{T-T_{b}}{T_{c r}-T_{b}}
$$$$
\tau_{0}=\frac{T_{\text {max }}-T_{b}}{T_{c r}-T_{b}}
$$ 


\section{REFERENCES}

1. K. Ishibashi, M. Wake, M. Kobayashi, and A. Katase, Cryogenics 19(11), 633-638 (1979).

2. M. N. Wilson and Y. Iwasa, Cryogenics 18(1), 17-25 (1978).

3. B. J. Maddock, G. B. James, and W. T. Norris, Cryogenics 2,261 (1969) .

4. V. E. Keilin, E. Yu Klimenko, M. S. Kremlev, and N. B. Samoilev, in "Les Champs Magnetiques Internes," CNRS, 231 (1967).

5. L. Dresner, IEEE Trans. Magn. 15(1), 328 (1979).

6. Trade-off studies similar to the one being done in this paper have been undertaken by $S_{1}$. Wipf in "Stability and Degradation of Superconducting Current-Carrying Devices," Los Alamos Scientific Laboratory Report LA-7275, Los Alamos, New Mexico (December 1978), p. 50 .

7. L. Dresner, J. R. Miller, and G. Donaldson, Proc. 6th Symp. on Engineering Problems of Fusion Research, p. 266 (1976).

8. R. G. Scurlock, Low Temperature Behavior of Solids, pp. 62-64, Dover, New York, 1966. 


\section{THIS PAGE}

\section{WAS INTENTIONALLY \\ LEFT BLANK}


ORNL/ TM-7517

Dist. Category UC-20 b

\section{INTERNAL DISTRIBUTION}

$\begin{aligned} 1 . & \text { R. A. Dory } \\ 2-\dot{6} . & \text { L. Dresner } \\ 7-11 . & \text { S. A. Elrod } \\ 12 . & \text { P. N. Haubenreich } \\ 13 . & \text { M. S. Lubel1 } \\ 14-17 . & \text { J. W. Lue } \\ 18-20 . & \text { J. R. Miller } \\ 21 . & \text { J. Sheffield } \\ 22 . & \text { A. Solomon } \\ 23 . & \text { W. C. T. Stoddart }\end{aligned}$

\author{
24-25. Laboratory Records Department \\ 26. Laboratory Records, ORNL/RC \\ 27. Document Reference Section \\ 28-29. Central Research Library \\ 30-31. Fusion Energy Division \\ Library \\ 32. Fusion En'ergy Division \\ Reports Office \\ 33. ORNL Patent office
}

\section{EXTERNAL DISTRIBUTION}

34. E. Adam, Airco, Inc., 100 Mountain Avenue, Murray Hill, NJ

35. Y. Aiyama, Electrotechnical Laboratory, 5-4-1 Mukodai-cho, Tanashi-City, Tokyo, Japan

36. D. J. Anthony, General Electric Company, Building 23, Room 290, 1 River Road, Schenectady, NY 12345

37. V. D. Arp, National Bureau of Standards, Boulder, CO 80302

38. M. P. G. Avanzini, Nucleare Italiana Reattori $\Lambda$ zanzati, NIRA S.p.A., Piazza Carignano, 2-16128 Genova, Casella Postale N. 1166,16100 Genova, Italy

39. D. Blackfield, Plasma Fusion Center, Massachusetts Institute of Technology, 167 Albany Street, Cambridge, MA 02139

40. G. Bogner, Forschungslaboratorien, Siemens Aktienge Sellshaft, Postfach 325, D8520 Erlanger 2, Federal Republic of Germany

41. A. Clark, National Bureau of Standards, Boulder, CO 80302

42. D. L. Coffey, American Magnetics, Inc., P.O. Box R, Oak Ridge, TN 37830

43. E. W. Collings, Battelle Memorial Institute, 505 King Avenue, Columbus, $\mathrm{OH} 43201$

44. R. W. Conn, Department of Chemical, Nuclear, and Thermal Engineering, University of California at Los Angeles, Los Angeles, CA 90024

45. S. 0. Dean, Director, Fusion Energy Development, Science Applications, Inc., 2 Professional Drive, Gaithersburg, MD 20760

46. H. Desportes, STIPE, CEN/Saclay, F91190, Gif-sur-Yvette, France

47. G. W. Donaldson, School of Electrical Engineering, University of New South Wales, P.0. Box 1, Kensington, New South Wales 2033, Australia

48. R. W. Fast, Manager, Experimental Facilities, Fermi National Accelerator Laboratory, P.0. Box 500, Batavia, IL 60510

49. F. Fickett, National Bureau of Standards, Boulder, CO 80302

50. J. File, Princeton University, Plasma Physics Laboratory, Princeton, NJ 08540 
51. H. K. Forsen, Laser Enrichment Department, Exxon Nuclear Company, Inc., 777 106th Avenue, NE, C-00777, Bellevire, WA 98009

52. H. P. Furth, Princeton University, Plasma Physics Laboratory, Princeton, NJ 08540

53. Y. Furuto, Chief of Superconducting Group, Central Research Laboratory, Furukawa Electric Company, Ltd., 9-15, 2-Chome, Futuba, Shinagawa-ku, Tokyo 141, Japan

54. W. F. Gauster, c/o H. Kirchmayr, Director, Institut fur Experimentalphysik, der Technischen Hochschule in Wien, A-1040 Vienna, Karlsplatz 13, Austria

55. E. Gregory, Airco Superconductors, 600 Milik St., Carteret, NJ 07008

56. D. S. Hackley, General Dynamics, Convair Division, P.0. Box 80847, San Dicgo, CA 22138

57. R. Hancox, UKAEA,' Culham Laboratory, Abingdon, Oxon, OX14 3DB, England

58. W. Heinz, Gesellschaft fur Kernforschung, Institut fur Experimental Kernphysik, 75 Karlsruhe, Postfach 3640, Federal Republic of Germany

59. C. D. Henning, Lawrence Livermore Laboratory, P.0. Box 808, L-535, Livermore, CA 94550

60. T. Hiraoka, Japan Atomic Energy Research Institute, Tokai Research Establishment, Tokai-mura, Naka-gun, Ibaraki-ken, Japan

61. R. L. Hirsch, Deputy Manager, Science and Technology Division, Exxon Corporation, 1251 Avenue of the Americas, New York, NY 10020

62. M. 0. Hoenig, Massachusetts Institute of Technology, National Magnet Laboratory, 170 Albany Street, Cambridge, MA 02139

63. R. Huse, Manager, Research and Development Department, PSE\&G Research Corporation, 80 Park Place, Newark, NJ 07101

64. M. Iwamoto, Central Research Laboratory, Mitsubishi Electric Corporation, 80 Nakano, Minamishimizu, Amagasaki, Hyogo Prefecture, Japan $660^{\circ}$

65. C. K. Jones, Manager, Cryogenic Research Laboratory, Westinghouse Eloctrio Corporation; Research aid Develupmenl Cenler, Plicsburgh, PA 15235

66. A. Knobloch, Max-Planck-Institut fur Plasmaphysik, Abteilung Technik, 8046 Garching bei Munchen, Federal Republic of Germany

67. P. Komarek, Institut fur Experimental Kernphysik, 75 Karlsruhe, Postfach 3640 , Federal Republic of Germany

68. K. Koyama, Electrotechnical Laboratory, 5-4-1 Mukodai-cho, TanashiCity, Tokyo, Japan

69. G. L. Kulcinski, Nuclear Engineering Department, 1500 Johnson Drive, University of Wisconsin, Madison, WI 53706

70. K. Kuroda, Hitachi, Ltd., Central Research Laboratory, 1-280, Higa Shiko Igakubo, Kokubumji, Tokyo 185, Japan

71. J. C. Lottin, CEN/Saclay, Dep. du Synchrotron Saturne, B.P. 2, 91 Gif-sur-Yvette, 91190, France

72. Max-P1anck-Institut fur Plasmaphysik, Hauptbibliothek, 8046 Garching bei Munchen, Federal Republic of Germany

73. F. Moon, Department of Theoretical and Applied Mechanics, Cornel1 University, Ithaca, NY 14850 
74. T. Ogasawara, Department of Physics, College of Science and Engineering, Nihon University, Kanada-Surugadai, Chiyoda-ku, Tokyo, Japan

75. H. Ogiwara, Toshiba'Research and Development Center, 1 Komukai Tsohibacho, Saiwai-ku, Kawasaki-C,ity, Kanagawa 210, Japan,

'76. J. Parain, CEN/Saclay, B.P. 2, F91190, Gif-sur-Yvette, France

77. $\therefore$ J. R! Pówel1, Brookhaven National: Labóratory, Upton, NY 11973

78. P. Reardon, Princeton University, Plasma Physics Laboratory, P.0. Box 451, Princeton, NJ 08540

79. R. P. Reed, National Bureau of Standards, Boulder, Co 80302

80. D. J. Rose, Department of Nuclear Engineering, Massachusetts Institute of Technology, Cambridge, MA 02139

81. G. Sacerdoti, Laboratorio Nazionali, Cas. Postale 70, 00044 Frascati, Italy

82. W. B. Sampson, Brookhaven National Laboratory, Upton, Long Island, NY 1197.3

83. Y. Sawada, Manager of Advanced Engineering Group, Heavy Apparatus Engineering Laboratory, Tokyo Shibaura Electric Co., Ltd. 4, 2-Chome, Suehiro-cho, Tsurumi-ku, Yokohama, Japan

84. K. Schmitter, Max-Planck-Institut fur Plasmaphysik, 8046 Garching bei Munchen, Federal Republic of Germany

85. J. Schultz, Massachusetts Institute of Technology, 167 Albany Street, Cambridge, MA 02139

86. S. Shimamoto, Japan Atomic Energy Research Institute, Tokai Research Establishment, Tokai-mura, Naka-gun, Ibaraki-ken, Japan

87. M. Spadoni, Laboratorio Nazionali, Cas. Postale 70, 00044 Frascati, Italy

88. S. St. Lorant, Stanford Linear Accelerator Center, Sand Hill Road, Palo Alto, CA 94304

89. L. D. Stewart, Princeton University, Plasma Physics Laboratory, P.0. Box 451, Princeton, NJ 08540

90. B. P. Strauss, Magnetic Corporation of America, 179 Bear Hill Road, Palo Al.to, CA 94304

91. K. Tachikawa, Chief of Electric Materials Laboratory, National Research Institute for Metals, 3-12, 2-Chome, Nakameguro, Meguru-ku, Tokyo, Japan

92. D. T. Uchida, Nuclear Engineering Department, University of Tukyu, Tokyo, Japan

93. S. T. Wang, Argonne National Laboratory, 9700 South Cass Avenue, Argonne, IL 60439

94. C. Waters, Technology Division, Building R25, Rutherford Laboratory, Chilton, Didcot, Oxfordshire, OX110QX, England

95. M. Wilson, Rutherford Laboratory, Chilton, Didcot, Oxfordshire, OX110QX, England

96. S. L. Wipf, Q-26, Los Alamoe Scientific Traboratory, P.0. Bóx 1663, Los Alamos, NM 87544

97. H. H. Woodson, Chairman, Department of Electrical Engineering, University of Texas, Austin, TX 78712

98. M. Yamamoto, Toshiba, Tsurumi Works, 4, Suehiro-choizchome, Tsurumi-ku, Yokohama, 230, Japan

99. K. Yasukochi', Department of Physics, College of Science and Engineering, Nihon University, Kanada-Surugadai, Chiyoda-ku, Toyko, Japan 
100. Uffice of Assistant Manager for Energy Research and Development, Department of Fnergy, Oak Ridge Operations Office, Oak Ridge, TN 37830

101-252. Given distribution as shown in TID-4500, Magnetic Fusion Energy (Distribution, Category UC-20 b, Magnetic Systems) 